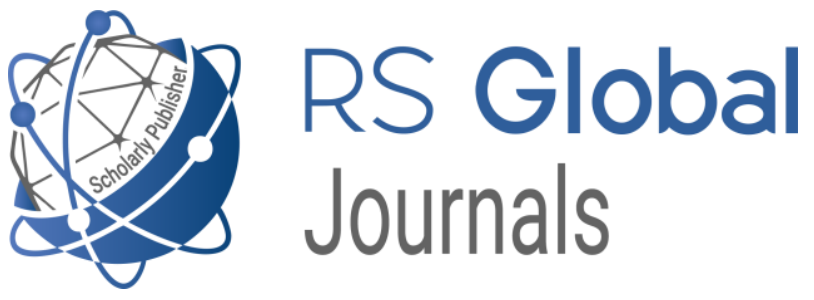

Scholarly Publisher

RS Global Sp. z O.O.

ISNI: 0000000484952390

Dolna 17, Warsaw, Poland 00-773

Tel: +48226022703

Email: editorial_office@rsglobal.pl

JOURNAL International Journal of Innovative Technologies in Social Science

p-ISSN

2544-9338

e-ISSN

2544-9435

PUBLISHER

RS Global Sp. z O.O., Poland

ARTICLE TITLE

AUTHOR(S)

ARTICLE INFO

DOI

RECEIVED

ACCEPTED

PUBLISHED

LICENSE
ADOLESCENTS' INVOLVEMENT IN SOCIAL MEDIA: BEFORE AND DURING COVID-19 PANDEMIC

Alisar Hudimova

Alisar Hudimova. (2021) Adolescents' Involvement in Social Media: Before and During Covid-19 Pandemic. International Journal of Innovative Technologies in Social Science. 1(29). doi: $10.31435 /$ rsglobal_ijitss/30032021/7370

https://doi.org/10.31435/rsglobal_ijitss/30032021/7370

12 December 2020

19 January 2021

24 January 2021

\section{(c) 0}

This work is licensed under a Creative Commons Attribution 4.0 International License.

(C) The author(s) 2021. This publication is an open access article. 


\title{
ADOLESCENTS' INVOLVEMENT IN SOCIAL MEDIA: BEFORE AND DURING COVID-19 PANDEMIC
}

\author{
Alisar Hudimova, \\ PhD Candidate in Psychology, Odesa I.I. Mechnikov National University, Odesa, Ukraine \\ ORCID ID: https://orcid.org/0000-0001-9996-0674
}

DOI: https://doi.org/10.31435/rsglobal_ijitss/30032021/7370

\section{ARTICLE INFO}

Received 12 December 2020

Accepted 19 January 2021

Published 24 January 2021

\section{KEYWORDS}

psychological well-being, adolescence, virtual communication, pathological involvement, social media, loneliness.

\begin{abstract}
Social media are an indispensable modern adolescents' daily ritual. The present study investigates the specifics of social media influence on the adolescents' psychological wellbeing in everyday life and during Covid-19. The research hypothesis stated that excessive social media use could provide loneliness, depression, and lack of sleep. The investigation is based on data received from interviews, questionnaires, and statistical analysis. A group of 516 psychology and medical students (78.8\% females, $21.2 \%$ males) aged 15-21 took part in the study via Google Form survey conducted in Odesa I.I. Mechnikov National University, Ukraine. The participants' overall well-being, loneliness, level of stress were assessed in correlation with personality characteristics and tendency to social media disorder. The obtained results showed that the more time adolescents spend on social media, the more real-life relationships decrease due to online isolation in social terms. The predictors of social media disorder are difficulties in relationships with family, time spent on social media and psychoemotional background. It is determined that the social media use creates the illusion of participation and importance for a large circle of people. The study provides evidence that the unsatisfactory level of modern adolescents' wellbeing can be explained by the passive use of social media, which provokes emotional lability, irritability, depression, and sleep deprivation.
\end{abstract}

Citation: Alisar Hudimova. (2021) Adolescents' Involvement in Social Media: Before and During Covid-19 Pandemic. International Journal of Innovative Technologies in Social Science. 1(29). doi: 10.31435/rsglobal_ijitss/30032021/7370

Copyright: (C) 2021 Alisar Hudimova. This is an open-access article distributed under the terms of the Creative Commons Attribution License (CC BY). The use, distribution or reproduction in other forums is permitted, provided the original author(s) or licensor are credited and that the original publication in this journal is cited, in accordance with accepted academic practice. No use, distribution or reproduction is permitted which does not comply with these terms.

Introduction. The study of computer-mediated communication has been the subject of research in various fields for 32 years. However, the study of social media influence on the psyche in psychological science is only relevant now. Such a disciplinary gap has contributed to the scarcity of resources. Social networking is a daily ritual for everyone. However, social media are the most popular among the younger generation. Therefore, because of the involvement of adolescents in various social media, the question of the relationship between their use and psychological health, including well-being, becomes crucial.

The age range of adolescence is constantly changing and may vary from decade to decade. The World Health Organization (WHO) has established chronological criteria that define adolescence as a life expectancy of 10 to 19 years, 11 months and 29 days (World Health Organization, 2005). However, this age stage can be divided into three periods: early (10-13 years), middle (14-16 years) and late (17-21 years) adolescence (World Health Organization, 2002). The World Health Organization categorizes 'young people' as adolescents and young people from 10 through 24 years of age (World Health Organization, 2014; Society for Adolescent Health and Medicine, 2017). Some researchers associated the social media use with individual characteristics of users. People with high levels of narcissism try to be as active on social networks as the latter is a platform for presenting themselves in a favorable light according to their ideal 'I' (Buffardi \& Campbell, 2008; Mehdizadeh, 2010). Wilson and colleagues 
(2010) found that such personal characteristics as extraversion, honesty, and self-esteem allow predicting both the amount of time spent on social media and the propensity to form an addiction. Many studies indicated that there is a link between social networking and compulsive behavior. The younger generation is concerned when does not have access to messages on social networks, which in turn leads to the development of phantom vibration syndrome. (Rosen et.al., 2012). Adolescents who are active users and spend more than two hours on social media are more likely to report mental health problems, including psychological disorders (anxiety and depression) (Sampasa-Kanyinga, and Lewis Rosamund, 2015). Some adolescents may be more vulnerable to developing symptoms of Internet addiction, including psychological manifestations and disorders, such as depression, attention deficit disorder and hyperactivity disorder due to their individual characteristics (Yen, Ko, et al., 2007). Kaur, Bashir (2015) examined both the positive and negative effects of social networks on adolescents' mental health. Among the positive influences were socialization, increased communication, learning opportunities and access to medical information. The negative aspects include depression, online harassment, cyberbullying, sexting, fatigue, stress, repression of emotional and intellectual abilities. The popularity of communication on social networks is spreading at a rapid pace among adolescents and, as a paradox, the current younger generation is more lonely, unlike other age groups. In this context, loneliness is seen as the difference between the desired and the real level of social contact. Uncontrolled, unhygienic and persuasive use of social media enhances loneliness. (Yao, et al., 2014).

Despite the active development of the concept and study of the connection of psychological well-being with various personality and social characteristics, the researches of scientists quite fragmented reflect the problem of psychological well-being fluctuation among adolescents involved in virtual communication. Thus, it can be stated that in our time social media have caused significant changes in the way people communicate and interact. However, it is unclear whether some of these changes may affect the norms of human behavior and cause mental disorders. Further investigation is needed to identify and describe potential links between virtual communication and psychological wellbeing. The subject of this study is the impact of social media on the psychological well-being of adolescents. A review and analysis of the literature have shown that most of the existing studies show a complex link between social networking and psychological well-being. This pattern is due to several factors, which include: the number of 'friends', the support level of online friends, loneliness, depression, and self-esteem. The use of social media has the effect of reducing the two components of psychological well-being: the current state of oneself and overall satisfaction with life.

The purpose of the study is to identify the relationship between the psychological disorders of adolescents and social media, including pathological involvement. The situation with worldwide isolation period has made it possible to study in more detail the social media impact on the adolescents' psychological state.

During the empirical work, the following hypotheses were put forward:

H1. Prolonged stay on social media leads to psychological disorders, in particular sleep disorders, anxiety, depression.

$\mathrm{H} 2$. The dominance of virtual communication is associated with the intensification of loneliness.

H3. Indifferent relationships within the family are predictors of adolescents' excessive attachment to social media.

H4. The desire to be aware of events in social media for more than 7 hours per day provokes the emergence of fear of missing out (FOMO), which is the trigger for the development of social media disorder.

H5. During self-isolation, the amount of time of social media's passive use increases.

H6. Changing daily tasks due to self-isolation leads to a long time online, which provokes disorders of sleep and the psychological state of adolescents.

\section{Materials and Methods.}

Participants.

Participants were adolescents $(\mathrm{N}=516)$ aged 15-21 years. Adolescents of this age group are the most active users of various social networking applications. The mean age of sample was 17 years $(\mathrm{M}=$ $17.92, \mathrm{SD}=3.003$ ). The study involved 406 girls and 110 boys. The study was conducted in form of handout questionnaires before quarantine and on platform Google Form during pandemic. A study provided in college and university, because of the need for an age category limited by the period of adolescence. Participation was voluntary, anonymous, no identifying information was collected. The sample size was determined by the number of students who correctly and entirely completed the questionnaires. The participants subsequently divided into two groups depending on the time spent on social media. 


\section{Materials.}

The research procedure consisted of filling out a questionnaire by respondents. Each questionnaire was accompanied by an instruction. The instruction indicated the study aspects, such as confidentiality, purpose and time. To collect data on the socio-demographic characteristics of adolescents, a specially designed questionnaire was used, the Freiburg Personality Inventory - B (Fahrenberg, Hampel \& Selg, 2010), the WHO-5 Well-being Index, The Warwick-Edinburgh Mental Wellbeing Scale (WEMWBS) (Tennant, et.al., 2007) was used to study the psychological and individual sphere (Bech, 2004; Topp, et al., 2015); The severity and type of the loneliness experience questionnaire (Korchagina, 2008); Social Media Disorder Scale (Eijnden, et. al., 2016). The questionnaires consisted of multiple-choice, rating scales (e.g. Likert scale) and closed-ended questions. Additionally, to assess the adolescents' condition due to the forced self-isolation during Covid-19 there were introduced some points as follows: 'Increasing of online communication', 'Behavior change', 'Feelings in connection with quarantine', 'The nature of opinions in connection with isolation', 'Frequency of fear associated with coronavirus', 'Frequency of social media use for distraction', 'Sleep changes'.

\section{Measures.}

\section{Social Media Loneliness.}

I assessed social media usage loneliness of adolescents using 30 items from Korchagina's (2008)_The severity and type of the loneliness experience questionnaire. All participants were asked by closed-ended questions with dichotomous answers: 'yes' or 'no'. The questions aimed to determine the level of loneliness experienced by a person at a given moment $(\alpha=0.77)$.

The precondition of Social Media Disorder. The participants were offered reliable and valid test FPI-B (Fahrenberg, Hampel \& Selg, 2010) to indicate their individual characteristics which have major influence on social media use $(\alpha=0.81)$. The FPI questionnaire contained 12 scales: neuroticism, spontaneous aggressiveness, depression, irritability, sociability, poise, reactive aggressiveness, shyness, openness, extraversion-introversion, emotional lability, masculinityfemininity. This 114-item questionnaire asked the respondents whether or not statements corresponded to some features of behavior, individual actions, attitude to people in different situations. Also, participants were asked a 5-item Likert - scale, which assessed preference to spend time online rather than meet in reality; to solve problems by immersion in social media; to neglect of sleep due to fear of missing something online. Ranging of scale from 1 (never) to 5 (all of the time).

The Social Media Disorder Scale has 2 forms: 27 and 9 statements. A dichotomous scale of 27 statements was developed to assess the nine DSM-5 dependence criteria, such as preoccupation, tolerance, withdrawal, displacement, escape, problems, deception, displace and conflict. This scale has a moderate relationship with depression, attention deficit, and the frequency of daily social media use, weak and moderate associations with loneliness, and impulsivity. However, only a weak negative association with self-esteem was found (Eijnden, et. al., 2016).

To investigate 203 adolescents a version with 27 statements was used, the reliability of the internal consistency $\alpha=0.85$, which indicates the high reliability of the scale. It should be mentioned that in the study of the authors of the method, this version of the scale showed a fairly high rate of internal consistency $\alpha=0.92$.

254 adolescents were tested with 9-item version during the quarantine period. Cronbach's alpha of this variant of diagnostic tool was 0.82 , which coincided with the result of the authors of the method.

To obtain data on family relationships, to estimate amount of time spent on social media, to study emotions adolescents experience during social media usage, there was developed and implemented a specially designed questionnaire.

Distinctness of Psychological Well-being due to Social Media Use. The measurement of social media impact on adolescents' psychological well-being was carried out by means of WHO-5 Well-being Index (Bech, 2004; Topp, et al., 2015). Did it have benefits or risks for the psychological state of young minds? The participants rated how they felt emotionally and physically in the past few weeks. Ranging of scale from 0 (at no time) to 5 (all of the time). WHO-5 was suitable for adolescents and to detect depression $(\alpha=0.86)$. Mean result for a total sample was $M=13.43, \mathrm{SD}=4.79$. The 14item Warwick-Edinburgh Mental Wellbeing Scale (WEMWBS) used to more detailed evaluation of adolescents' mental well-being $(\alpha=0.85)$. Participants rated statements which described their experience over the last 2 weeks. In this questionnaire used scale from 1 (none of the time) to 5 (all of the time). Mean result for sample was $\mathrm{M}=47.81, \mathrm{SD}=9.93$. During quarantine adolescents demonstrated advanced level of psychological well-being: $\mathrm{M}=48.66, \mathrm{SD}=8.35$. 
Procedure.

Participants were invited to participate in the study through personal testing and information on educational sites. Respondents were given information that the study was anonymous and conducted to examine the social media influence on the psychological state of their age group. All participants indicated that they understood the risks and wished to participate in the study. The test time was unlimited, but the average time of completion was 30 minutes. The study was conducted in a form convenient for participants, either a paper or a computer version. Each participant had own individual table. Such a measure was used to avoid group influence on results.

In this study were undertaken four steps: 1) Dividing sample to measure the amount of social media usage; 2) Determination of study boundaries; 3) The completion of the Questionnaire to determine the severity and type of the loneliness experience, Freiburg personality inventory test, Social Media Disorder Scale and socio-demographic questionnaire; 4) Statistical analysis was used.

Results. The survey showed that modern adolescents started using social networks at an early age, with an average of 7 years of use $(\mathrm{M}=6.96, \mathrm{SD}=2.39)$. The analyses demonstrated that social media do contribute to the symptoms of anxiety and depression $(r=0,348 / \rho \leq 0,007)$.

Correlation relationships of the studied components determined to test the hypothesis that prolonged stay in social media leads to psychological disorders, including sleep disturbance, anxiety, depression (see Table 1).

Table 1. Ranked correlative relationships of time spent on social media with psychological disorders and family relationships

\begin{tabular}{|l|l|}
\hline $\begin{array}{l}\text { Time spent on social media with } \\
\text { psychological disorders }\end{array}$ & Relationships in the family \\
\hline $\begin{array}{l}\text { Solving problems in social media: } r=0,375 ; \\
\rho \leq 0,003\end{array}$ & State of loneliness: $r=0,427 ; \rho \leq 0,001$ \\
\hline Diffuse loneliness: $r=0,327 ; \rho \leq 0,015$ & Diffuse loneliness: $r=0.405 ; \rho \leq 0,001$ \\
\hline Interest: $r=0.321 ; \rho \leq 0,015$ & Poise: $r=-0.370 ; \rho \leq 0,04$ \\
\hline Joy: $r=0.411 ; \rho \leq 0,001$ & Spontaneous aggressiveness: $r=0,365 ; \rho \leq 0,005$ \\
\hline Imbalance: $r=0.261 ; \rho \leq 0,05$ & Emotional lability: $r=0,311 ; \rho \leq 0,015$ \\
\hline & Shyness: $r=0.301 ; \rho \leq 0.02$ \\
\hline & Subjective health assessment: $r=0.280 ; \rho \leq 0,01$ \\
\hline & Sleep Disorders: $r=0.279 ; \rho \leq 0,03$ \\
\hline & Dissociated loneliness: $r=0.278 ; \rho \leq 0,03$ \\
\hline
\end{tabular}

One of the goals of the study was to find such complex factors that could more fully explain the cause-effect relationships between the survey variables of respondents involved in virtual communication. For this purpose, factor analysis with subsequent orthogonal rotation by the Varimax-Kaiser method was used. The variables inside each block were sorted in descending order of factor loadings greater than 0.4.

According to the data of the scree plot, there are from 2 to 4 factors (see Figure 1). The first factor included the emotional component of social media, in particular, neuroticism and aggression; the WHO-5 Well-being Index. The second factor included somato-vegetative (Neurotic) and Masculinity-femininity scales of FPI questionnaire, the WHO-5 Well-being Index and stress level. The third factor is Masculinity - Femininity and FPI Behavior Scales.

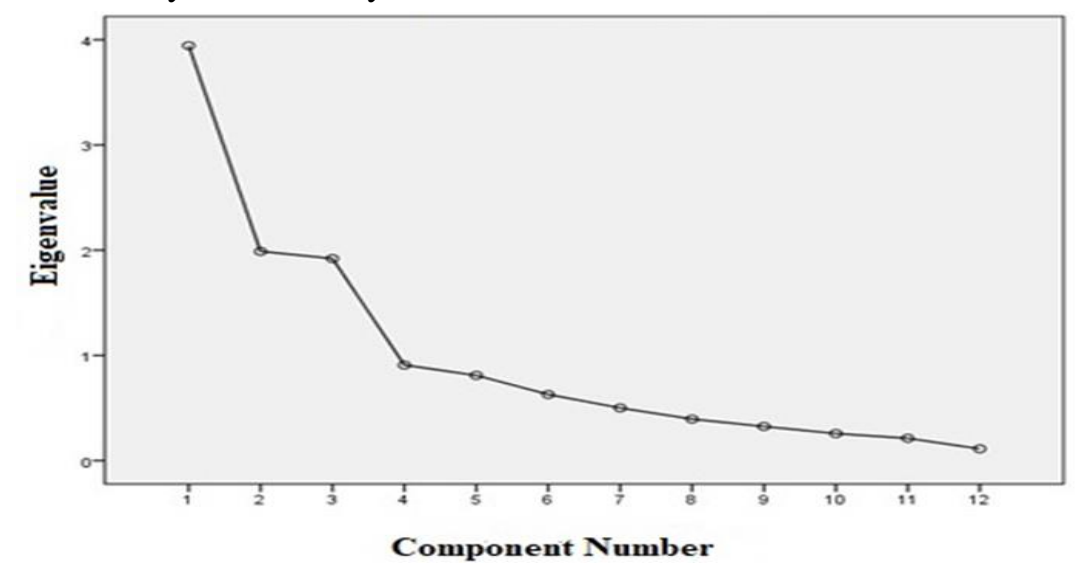

Fig. 1. Social media influence on adolescents' psychological well-being before quarantine 
As shown in Table 2, to reflect the deep processes that explained complex phenomena, factor analysis was applied using the principal component method.

Table 2. Factor analysis - Varimax - by Kaiser (cumulative $=70.7 \%$ )

Matrix of Orthogonal rotation of components *

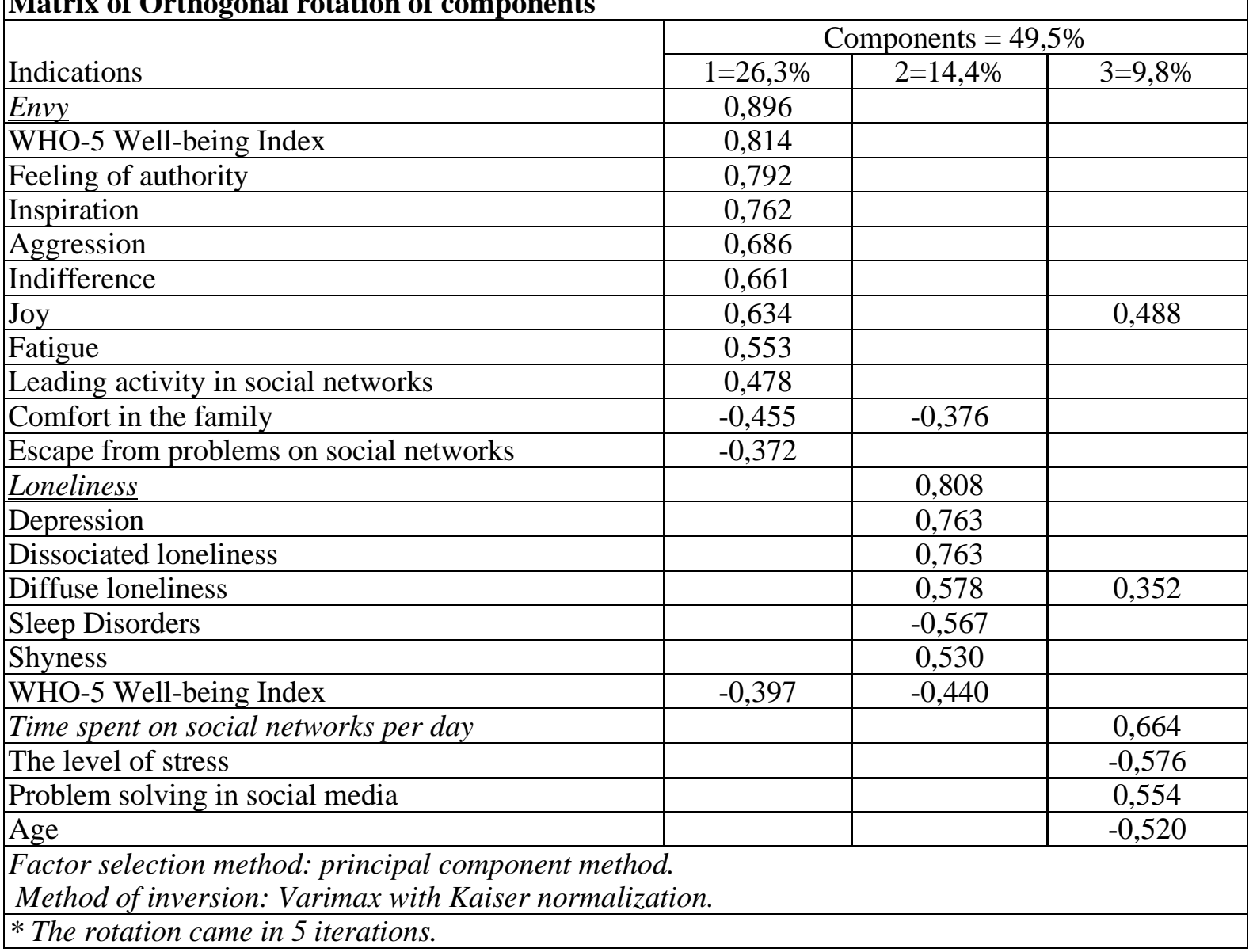

Fundamentally important was to compare the social media's impact on the adolescents' psychological state within the period before and during the quarantine.

Comparing the specificity of the psychological consequences of uncontrolled online presence is a new complex phenomenon, the study of which is relevant (Table 3).

Table 3. Comparison of adolescents' profiles involved in the social media in the period before imposing a quarantine (1) $\mathrm{N}=262$, and in the period of self-isolation (2) $\mathrm{N}=254$

\begin{tabular}{|c|c|c|c|c|c|}
\hline \multirow{2}{*}{ Indicator } & \multirow{2}{*}{$\begin{array}{l}\text { Everyday life/ } \\
\text { Self-isolation }\end{array}$} & \multicolumn{2}{|c|}{ Mean } & \multirow[b]{2}{*}{$\% \%$} & \multirow{2}{*}{$\rho$} \\
\hline & & $\mathrm{M}$ & $\pm \mathrm{m}$ & & \\
\hline \multirow{2}{*}{$\begin{array}{l}\text { Number of social } \\
\text { media's } \\
\text { accounts }\end{array}$} & 1 & 2,45 &, 104 & \multirow{2}{*}{$82,2 \%$} & 3,98 \\
\hline & 2 & 2,98 & ,083 & & 0,05 \\
\hline \multirow{2}{*}{ Displace } & 1 & 5,02 &, 162 & \multirow{2}{*}{$210 \%$} & 4,05 \\
\hline & 2 & 2,39 & 079 & & 0,05 \\
\hline \multirow{2}{*}{ Loneliness } & 1 & 29,28 & ,640 & \multirow{2}{*}{$106 \%$} & 2,33 \\
\hline & 2 & 27,65 &, 263 & & 0,05 \\
\hline
\end{tabular}

The connection between psychological disorders and the unhygienic use of social media is a complex and ambiguous phenomenon. To verify the feasibility of the results obtained during the study, the factor analysis was conducted.

Figure 2 shows the 'break' of the graph from the first to the second factor. This states that the optimal number of factors is two. 


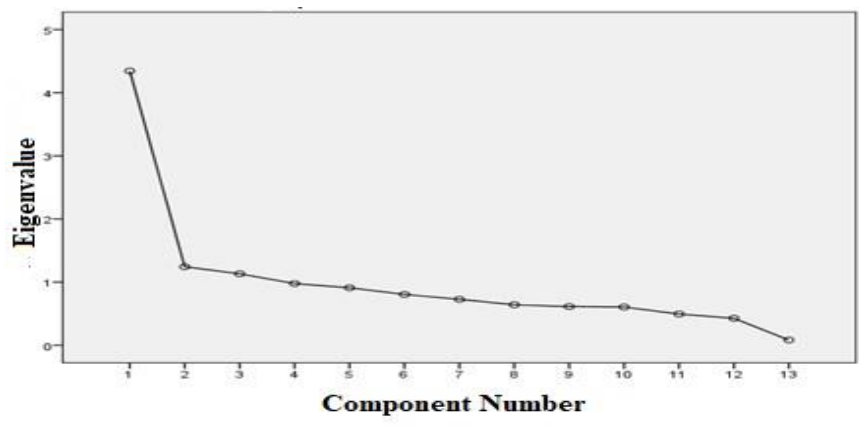

Fig. 2. Social media and adolescents' psychological state interrelation during quarantine

The factor analysis with the rotation of the Kaiser varimax allowed to identify the following factors, which are reflected in Table 3.

Table 3. Inverse matrix of components

\begin{tabular}{|l|c|c|}
\hline \multicolumn{1}{|c|}{ Indicator } & \multicolumn{2}{c|}{ Component } \\
\cline { 2 - 3 } & 1 & 2 \\
\hline Social Media Disorder Scale & 0,789 & 0,454 \\
\hline Preoccupation & 0,731 & \\
\hline Tolerance & 0,722 & \\
\hline Time spent on social media per day & 0,631 & \\
\hline Number of social media's accounts & 0,553 & \\
\hline Escape from bad thoughts in social media & 0,549 & \\
\hline Escape & 0,504 & $-0,668$ \\
\hline Sense of self during isolation & & 0,535 \\
\hline Loneliness & & $-0,520$ \\
\hline Behavior change due to quarantine & & $-0,514$ \\
\hline Warwick-Edinburgh Mental Wellbeing Scale & & 0,512 \\
\hline Sleep Changes & & 0,508 \\
\hline Conflict & & \\
\hline $\begin{array}{l}\text { Factors selection method: principal components method. } \\
\text { Rotation method: varimax with Kaiser normalization. }\end{array}$ & \\
\hline The rotation converged in 3 iterations. & & \\
\hline
\end{tabular}

During quarantine, involvement in the virtual world increases excessively, which leads to adolescents' insomnia. According to the survey, was found that $26 \%$ of adolescents neglect sleep, spending all night on social media, and go to bed in the morning. This sleep pattern leads to disturbances of health and psychological distress (Figure 3).

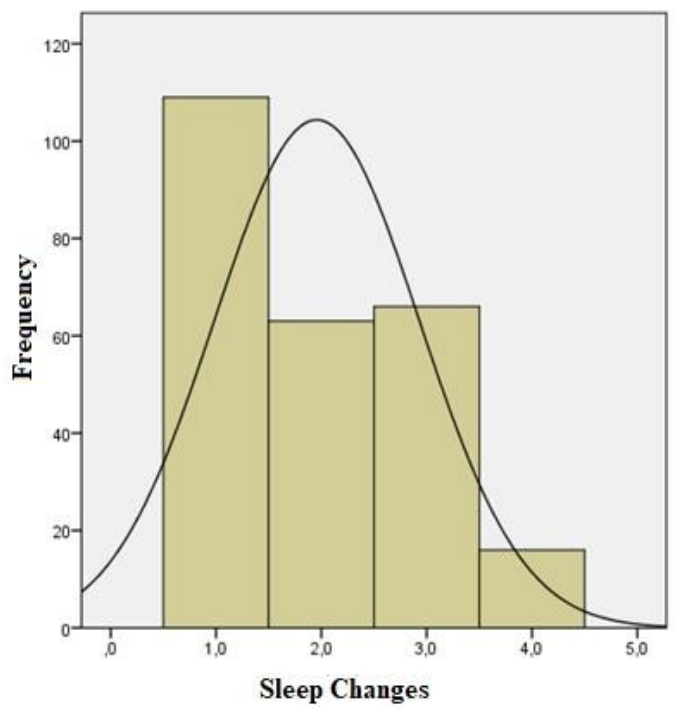

Fig. 3. Histogram of adolescents' sleep changes due to the social media use 
Discussion. The study aimed to identify the relationship between the psychological disorders of adolescents and social media. Social media significantly change the nature of interpersonal relationships. Adolescents with pathological involvement often prefer virtual communication, neglecting social activities, personal communication, and family conflicts.

An emotional state can be a mediator between time spent on social media and the quality of family relationships. Emotional support is very important in everyone's life because its low level is associated with mental and physical health problems, which in turn negatively affect psychological wellbeing. Adolescents often flee the virtual environment to get rid of negative experiences or use their blogs as a means to solve problems and seek support from subscribers. Social media are the most effective platform for getting approval, support, but it can also have negative effects in the form of cyberbullying. The findings revealed that the overuse of social media leads to a decrease in real communication, anxiety and relationship problems. Adolescents start to distinguish themselves from others, creating a basis for social and emotional loneliness. The revealed relationship of time spent on social media and adolescents' joy, interest and the tide of forces can be explained by the presence of a large audience, which is associated with the ability to maintain a positive virtual image through the likes and comments of other users. In addition, adolescents emphasize the importance of receiving information about various events, music updates and changes in the lives of virtual friends. They prefer frequent checking of social networking applications as it is a convenient information platform in which fun and relaxed content are provided. Among the surveyed adolescents, there is a tendency of imbalance, characterized by the removal of their posts, if they do not collect the desired number of 'likes'. Additionally, to attract attention, some adolescents may delete their account to see for whom they are important. Relationships in the family have a significant impact on the degree of activity of adolescents on social media. The frequency of social networking is negatively correlated with time spent with the family and correlates positively with family conflicts, leading to low levels of family cohesion. Due to the imitation of communication and involvement in the life of virtual friends, adolescents have a feeling of loneliness. This pattern can be explained by the fact that being in virtual space adolescents compare their lives with other users. Such comparison creates the basis for the development of depression. As a result of excessive social media use and identification with idols or the lives of 'more successful and happy' users, adolescents provoke the emergence and development of diffuse loneliness.

Therefore, it can be concluded that social media overload and conflicts in the family because of virtual communication can significantly impair mental health, in particular, psychological wellbeing in adolescents.

Factor analysis showed that adolescents' leading activity in social media is not communication, but passive social media use (scrolling news feeds, watching videos and so-called tracking, and viewing pages of other users). Such activity gradually blurs attention and moves it away from useful activities, such as expressing creativity or doing deep work, to comparison, envy, and concern for one's status. Ongoing chases of 'likes' and subscribers lead to a comparison of adolescents with other more popular bloggers, which has negative effects on self-presentation and psychological well-being. Receiving negative or missing feedback leads to seclusion, indifference and provokes feelings of loneliness and hopelessness. Shyness as a form of social anxiety interferes with real interpersonal communication, that is why adolescents prefer virtual communication. This social networking advantage is bipolar, as it can further deepen shyness. Shyness is inextricably linked to real or perceived interpersonal rejection, loneliness, and depression. Spending a big amount of time on social media exacerbates the feeling of social isolation and provokes sleep deprivation. Sleep disorder in the form of insomnia and hypersomnia may manifest the depressive syndrome. Dissociated loneliness is caused by a change in the mechanisms of identification and alienation concerning the same subject if it sees its negative traits, and diffuse loneliness is characterized by dissatisfaction with one's life and copying of the identity and behavior of the subject of identification. In the case of social media, this is due to the need to feel and fit into the social community, without trying to overcome their protective mechanisms and social anxiety. The factor of time spent on social media per day indicates that prolonged stay in the virtual space is a source of stress.

Adolescents overuse social media as a means of avoiding problems. It is established that the number of social media in which the respondents have accounts does not affect the development of social media disorder and the psychological well-being of adolescents. Increasing time spent online can be associated with finding new online friends or keeping in touch with real acquaintances and friends. The last can predict the development and reinforcement of addictive behavior. Social media addiction depends not on one single factor, but the complex: time spent online, relationships in the family and 
close circle. Social media have some influence on overall health: from providing access to medical and interesting information related to the course and treatment of illnesses, to reducing adolescents' physical activity due to frequent virtual space indirectly via smartphones or other gadgets. There is a great deal of research by scientists to report sleep disorders related to social networks (Exelmans, Van den Bulck, 2016; Cain, Gradisar., 2010; Gringras, et al., 2015). However, our study found that adolescents have sleep disorders in rare cases, manifested as superficial sleep, insomnia, and late waking. The link between pathological involvement in social media with diffuse loneliness was established.

The situation during pandemic demonstrated that during quarantine, the number of social media accounts increased among adolescents, due to registration in different platforms (e.g., TikTok, Snapchat, Pinterest). This trend can be explained by fatigue from the monotony of the proposed content on platforms such as Facebook, Instagram, Telegram; desire to try something new; creating original content or participating in various challenges and expanding the social community for interaction. Isolation exacerbates adolescents' sense of belonging. A sense of belonging is a psychological state that reflects a desire to be part of a community in an online social environment (Cheung, et. al., 2011). Multitasking at the time of using various social networking applications leads to meeting the need for affiliation and conditional socialization. Active interaction with other users and the inclusion of attention in watching a variety of videos and reading articles helps to distract from problems, as well as to some extent reduces the feeling of social isolation. Sense of belonging is the psychological state of being part of the community in an online social network (Cheung, et. al., 2011).

During the quarantine, some social networking applications, in particular: Zoom, Viber, Google Classroom, became quite relevant, because thanks to them, study process continued. However, this research focuses on more popular platforms that provide an entertaining effect on adolescents. The latter is inextricably linked to the hedonistic part of well-being, as being on social media produces a sense of interest, satisfaction, and a constant desire to reinforce a sense of euphoria that has a significant impact on the formation of compulsive online behavior. Conditionally a lot of free time leads to an uncontrolled stay on social media. Adolescents spend a lot of time on gadgets to do homework, having free access to distraction through social networking applications. Being able to take a break from tasks often leads to switching between different social platforms. Such online behavior leads to compulsive use of social media. When it is impossible to check social media, adolescents experience the so-called 'withdrawal syndrome', which is accompanied by mood swings and obsession to return to virtual friends as soon as possible.

Adolescents, regardless of environmental conditions, occasionally feel lonely. This can be due to a sense of uniqueness, shyness, misunderstanding with others, and immersion in social media. Social media in the context of mine study have an ambivalent effect on the experience of loneliness. On one hand, adolescents communicate with virtual friends and meet the need for social affiliation. On the other hand, by watching news feeds and photos of other users, adolescents feel isolated and uninteresting because no one spends time with them in this way. Therefore, when interpreting the data obtained, it is important to remember that loneliness is a subjective feeling by which a person sees his or her reality. Masi's study states that a person may feel lonely, even when surrounded by people or may feel socially satisfied, even if they are part of a small number of social connections (Masi, 2011).

The results of the study showed that due to forced self-isolation, adolescents experience significant psychological stress due to fear of the unknown and a change in the usual rhythm of life. As a coping strategy, adolescents choose the easiest possible way to displace bad thoughts - focusing on the virtual world and creating their virtual image, through which they can support the basic mechanisms of socialization. After all, social media mimic ordinary life, the only difference is the distance between users. Actively communicating with acquaintances, adolescents do not lose the skills of maintaining contact with others, take part in the discussion of topics of interest to them. With passive social media use, which includes watching the feed, posting, photos, commenting on other users' posts, and waiting for reactions to their posts, adolescents experience the illusion of community involvement. The last pattern of social media usage often leads over time to depression, anxiety, and feelings of isolation from the outside world. The first factor indicates that there is a link between the manifestations of social media disorders and the desire of adolescents to displace bad thoughts through spending time online. The ability to freely switch between different social media accounts allows you to keep abreast of the latest developments, to communicate with other users indirectly with likes, comments, and reposts. This type of interaction produces a sense of belonging to the community, as well as reduces feelings and helps to distract from a stressful situation. It can be stated that adolescents use social networks as a shelter, where it is possible to use the settings to filter the information that 
will appear in the feed. By creating a safe news feed, adolescents feel safe and focus on the positive. Thus, I found that modern adolescents are prone to escapism during isolation. In 2017, scientist Young defined the term 'escapism'. Escapism is a behavior used to distract oneself from real-life problems (Young, 2017). Thus, in mine study, this statement was mathematically validated.

Conclusions. It can be stated that the level of adolescents' pathological involvement in social media can be associated with subclinical depression, anxiety, loneliness, feeling of constant tension and subjective stress. Manifestations of depression are associated with frequent use of social media during the day. It caused by disappointment in lack of self-control, fluctuations in self-esteem due to comparison with more popular users, a sense of worthlessness through cyberbullying, or lack of feedback, which is significant. All of these factors reduce psychological well-being. The illusion of involvement does not diminish the feeling of loneliness, but only reinforces it through rewards in the form of likes and subscribers, captivating design and content of almost every social platform, forcing you to check updates frequently. However, such features of social media mimic rather than satisfy the need for attention.

Both in everyday life and during quarantine due to social media use, adolescents have sleep disorders. With the increase in the amount of time spent on virtual communication, there are significant changes in the level of psychological well-being of adolescents. I found that active users have low self-esteem, and sleep disturbances. The negative consequences of social media usage for the adolescents' psychological well-being are associated with the chosen type of social networking behavior that does not meet the need for acceptance and belonging to the community. The study complements and confirms the results of other researchers that the use of social media can affect sleep by increasing cognitive arousal (Cain, 2010; Van den Bulck, 2004; Exelmans, 2017). Cognitive arousal is largely related to the ability to create content and interact with a large number of users simultaneously. The focus of social media affects not only sleep but also the emotional state and sense of socialization. Receiving reactions or in their absence, adolescents may experience a surge of energy, satisfaction, and involvement in the community, as well as anxiety, tension, feelings of worthlessness, and isolation from others.

Of course, not all adolescents have sleep problems during isolation due to activity on social media (42.9\%). Only $6.3 \%$ of adolescents suffer from insomnia due to an obsessive desire to check for updates in applications and watch a variety of videos from which it is difficult to break away. According to the interviews, adolescents noted that quite often before going to bed they start looking at recipes, dance tutorials, make-up tutorials, and top 40 reasons to overcome insomnia, which eventually leads to sleep-wake cycle disorders.

According to the results, adolescents with a level of psychological well-being from 47 to 69 points do not have problems with sleep. The survey revealed that with the right daily routine and the efforts of the will, adolescents are able to stop being in the virtual world and prepare for sleep.

The results of the survey 'How do you feel about quarantine?' found that adolescents prefer to be distracted by watching TV series, spending time on social media and reading various blogs and that a large number of homework assignments help shift the focus from isolation. Often adolescents spend a lot of time on social media to take a break from homework, and as a result, spend the whole day online. Due to such an unhygienic distribution of time, adolescents disrupt the normal regime of rest and work.

The study has several limitations. One major limitation lies in the way of the data collection. The research only included Ukrainian adolescents as participants. Therefore, to further test the psychometric properties of the diagnostic materials, cross-cultural studies should also be conducted in the future using different adolescent groups in different countries.

The causal linkages of well-being dependence on social media use are complex and ambiguous, resulting in a growing role for longitudinal observations of adolescents.

\section{Acknowledgments.}

I would like to say a special thank you to my supervisor, prof. Psiadlo E. His support, guidance and overall insights in psychology and psychometrics have made this an inspiring experience for me.

I would like to thank my family for supporting and encouraging me during the compilation of this research, especially, big gratitude to my grandmother Olha Holovko.

Finally, I would also like to thank all of the participants in the study's interviews and surveys.

Declaration of Interest Statement.

I have no conflicts of interest to disclose. 


\section{REFERENCES}

1. Adolescence: A period needing special attention. (2014). Health for the World's adolescents report. Geneva: World Health Organization; Available at: http://apps.who.int/adolescent/seconddecade/section2/page1/recognizing-adolescence.html.

2. Bech P. (2004). Measuring the dimensions of psychological general well-being by the WHO-5. QoL Newsletter, 32, 15-16.

3. Buffardi, E. L., \& Campbell, W. K. (2008). Narcissism and social networking web sites. Personality and Social Psychology Bulletin, 34, 1303-1314. https://doi.org/10.1177/0146167208320061

4. Cain N., Gradisar M. (2010). Electronic media use and sleep in school-aged children and adolescents: A review. Sleep Med. Sep, 11 (8), 735-42. https://doi.org/10.1016/j.sleep.2010.02.006. Epub 2010 Jul 29. et al

5. Cheung, Christy \& Chiu, Pui-Yee \& Lee, Matthew. (2011). Online Social Networks: Why do Students use Facebook? Computers in Human Behavior. 27. 1337-1343. 10.1016 / j.chb.2010.07.028.

6. Eijnden, Regina \& Lemmens, Jeroen \& Valkenburg, Patti. (2016). The Social Media Disorder Scale: Validity and psychometric properties. Computers in Human Behavior. 61. 478-487. 10.1016/j.chb.2016.03.038.

7. Exelmans L, Van den Bulck J. (2016). The use of media as a sleep aid in adults. Behav Sleep Med, 14 (2), 121-133. https://doi.org/10.1080/15402002.2014.963582.

8. Fahrenberg, J., Hampel, R. \& Selg, H. (2010). Freiburger Persönlichkeitsinventar (8., erweiterte Aufl.). Göttingen: Hogrefe.

9. Gringras P, Middleton B, Skene DJ, Revell VL. (2015). Bigger, brighter, bluer-better? current lightemitting devices - adverse sleep properties and preventive strategies. Front Public Health, 3, 233. https://doi.org/10.3389/fpubh.2015.00233.

10. IBM Corp. (2015). IBM SPSS Statistics for Windows, Version 23.0. Armonk, NY: IBM Corp

11. Kaur, R. \& Bashir, H. (2015). Impact of Social Media on Mental Health of Adolescents. International Journal of Education, 5, 22-29. https://doi.org/10.25215/0403.134

12. Korchagina S.G. (2008). The psychology of loneliness: a textbook. - Moscow: Moscow Psychological and Social Institute.

13. Masi, C. M., Chen, H. Y., Hawkley, L. C., \& Cacioppo, J. T. (2011). A meta-analysis of interventions to reduce http://hes.ccsenet.org Higher Education Studies Vol. 9, no. 2; 201920 loneliness. Personality and Social Psychology Review, 15 (3), 219-266. https://doi.org/10.1177/1088868310377394

14. Rosen, L. D., Cheever, N. A., \& Carrier, L. M. (2012). iDisorder: Understanding our obsession with technology and overcoming its hold on us. New York, NY: Palgrave Macmillan

15. Sampasa-Kanyinga Hugues and Lewis Rosamund F. (2015). Frequent Use of Social Networking Sites Is Associated with Poor Psychological Functioning Among Children and Adolescents. Cyberpsychology, Behavior, and Social Networking, 18(7), 380-385.http://doi.org/10.1089/cyber.2015.0055

16. Society for Adolescent Health and Medicine (2017). Young Adult Health and Well-Being: A Position Statement of the Society for Adolescent Health and Medicine. The Journal of adolescent health: official publication of the Society for Adolescent Medicine, 60(6), 758-759. https://doi.org/10.1016/j.jadohealth.2017.03.021

17. Tennant, R., Hiller, L., Fishwick, R., Platt, S., Joseph, S., Weich, S., Parkinson, J., Secker, J., \& StewartBrown, S. (2007). The Warwick-Edinburgh Mental Well-being Scale (WEMWBS): Development and UK validation. Health and Quality of Life Outcomes, 5, Article 63. https://doi.org/10.1186/1477-7525-5-63

18. Topp, Christian \& Østergaard, Søren \& Søndergaard, Susan \& Bech, Per. (2015). The WHO-5 Well-Being Index: A systematic review of the literature. Psychotherapy and psychosomatics, 84, 167-176. https://doi.org/10.1159/000376585

19. Van den Bulck J. (2004) Television viewing, computer game playing, and Internet use and self-reported time to bed and time out of bed in secondary-school children. Sleep.; 27 (1): 101-4.

20. Wilson, K., Fornasier, S., \& White, K. M. (2010). Psychological predictors of young adults' use of social networking sites. Cyberpsychology, Behavior, and Social Networking, 13, 173-177. https://doi.org/10.1089/cyber.2009.0094

21. World Health Organization. (2002). Breastfeeding and maternal medication: recommendations for drugs in the Eleventh WHO Model List of Essential Drugs. World Health Organization. https://apps.who.int/iris/handle/10665/62435

22. World Health Organization. (2005). Nutrition in adolescence: issues and challenges for the health sector: issues in adolescent health and development. World Health Organization. https://apps.who.int/iris/handle/10665/43342

23. Yao, M. Z., \& Zhong, Z. J. (2014). Loneliness, social contacts and Internet addiction: A cross-lagged panel study. Computers in Human Behavior, 30, 164-170. https://doi.org/10.1016/j.chb.2013.08.007

24. Yen, Ju-Yu \& Ko, Chih-Hung \& Wu, Hsiu-Yueh \& Yang, Ming-Jen. (2007). The Comorbid Psychiatric Symptoms of Internet Addiction: Attention Deficit and Hyperactivity Disorder (ADHD), Depression, Social Phobia, and Hostility. The Journal of adolescent health: official publication of the Society for Adolescent Medicine, 41, 93-8. https://doi.org/10.1016/j.jadohealth.2007.02.002. PubMed: 17577539

25. Young, N. L., Kuss, D. J., Griffiths, M. D., \& Howard, C. J. (2017). Passive Facebook use, Facebook addiction, and associations with escapism: An experimental vignette study. Computers in Human Behavior, 71, $24-31$. 